\title{
LAND DEGRADATION IN THE CALORIE MODEL: DYNAMICS OF THE STATIONARY STATE
}

\author{
Martin Machay ${ }^{1}$ \\ ${ }^{1}$ Department of Economics, Faculty of Business and Economics, Mendel University in Brno, Zemědělská 1, 61300 \\ Brno, Czech Republic
}

To cite this article: Machay Martin. 2018. Land Degradation in the Calorie Model: Dynamics of the Stationary State. Acta Universitatis Agriculturae et Silviculturae Mendelianae Brunensis, 66(6): 1543-1547.

To link to this article: https://doi.org/10.11118/actaun201866061543

\begin{abstract}
The environmental aspects play more and more important role in an economic life of the society. One aspect the Classics did not see clearly in the context of the stationary state. This paper explores implications of the introduction of the land degradation into the concept of the classical stationary state. The calorie model is used to model the dynamics of the stationary state. Several new theorems are derived in the paper. The variables of interest are interdependent. The dynamics of the stationary state is, hence, conditional. The stationary state is more sensitive to the land degradation under contemporary conditions than to the population growth. This explains its increasing role in economic policy and economic discussions.
\end{abstract}

Keywords: stationary state, food, population, calorie model, land degradation

\section{INTRODUCTION}

The sciences have put growing emphasis on the environmental aspects of economic activity in recent decades.

The beginnings of a coexistence between economics and environmental sciences were not without complications (Oates, 1990; Babe, 2006). Not only the theory of externalities has emerged within economics but a whole new branch of economic theory has eventually been established - environmental economics (Cameron, 1997; Diets and van der Straaten, 1992; Castle, 1999; Timmins and Schlenker, 2009) with all its pros and cons. Various economic schools have been examined for their attitude towards environment (Soderbaum, 1990; Gowdy, 2004; Nadeau, 2006; Berger and Forstater, 2007; Carlsson and Johansson-Stenman, 2012). Even though the environmental economics is naturally very close to the agricultural economics (Kling et al., 2010) the origins of environmental economics can be tracked to Malthus himself (Mayhew, 2014).

While the population theories lost their attractiveness due to accelerated technological growth and dropping fertility rates in the developed parts of the world the environmental damage caused by production is gaining strength. While deforestation is an issue that the governments try to solve the frequency of deforestation remains unchanged (Rosa et al., 2012; Gonzalez-Jaramillo et al., 2016; Bowers et al., 2017). It is easy to analyse individual harms to the environment or to focus on a single industry. The global level of analysis has been unfortunately restricted to the deforestation.

With deforestation and more intensive agriculture the land degrades. Naturally, a question about possible consequences of land degradation for the Malthusian stationary state arises.

While contemporary environmental economics is advanced in comparison with Malthusian framework one may wonder whether Malthus was 
aware that variating ways of using the land will affect its productive power. He probably didn't put emphasis on it because it was not the topic of his days. The situation has changed.

The aim of this paper is, thus, to explore implications of the introduction of land degradation into the concept of the classical stationary state. It explores the variations in productive power of land within the Malthusian framework. The next part of the paper introduces after a brief review of basic principles of the calorie model the land degradation as a new variable into the model.

\section{Malthus and land degradation}

It is well known that the Malthusian principle is mostly based on the land limitation. Let us speak Malthus for himself:

"Every acre of land has been so long in cultivation, that we can hardly conceive there is any great yearly addition to the average produce." (Malthus, 1798: ch. IV)

The limit for population is not only given by the fixed amount of land - hence, productive power of land - but by the human capability to boost this power as well - productive power of men. Little is known that Malthus did notice another power in play all those years ago and so long before environment became a topic of economic discussions and inquiries. Malthus declared:

"That the produce of the land has been decreasing, or even that it has been absolutely stationary during the last century, few will be disposed to believe. The inclosure of commons and waste lands, certainly tends to increase the food of the country; but it has been asserted with confidence, that the inclosure of common fields, has frequently had a contrary effect; and that large tracts of land which formerly produced great quantities of corn, by being converted into pasture, both employ fewer hands, and feed fewer mouths, than before their inclosure." (Malthus, 1798: ch. XVI)

Using land in an improper way has a "contrary effect". Malthus was aware that not only the quantity of land was a limiting factor for the population growth but he highlighted a possible misuse of the land as well. Land degradation, fruits of land and its capability to feed the population to be more precise, endangered the sustainability of the path towards the stationary state.

"The present system of grazing, undoubtedly tends more than the former system to diminish the quantity of human subsistence in the country, in proportion to the general fertility of the land." (Malthus, 1798: ch. XVI)

The logical conclusion was that the ability of the land to sustain the population weakened as the land was misused causing increasing tensions in the area of the maintenance of labor. As a consequence, the misused land would worsen the conditions of the laboring poor.

It is a natural step to incorporate the land degradation into the model representing the classical stationary state. The classical stationary state was formalized in the form of the Calorie model in 2012 (Machay) and expanded by the death rates in 2016 (Machay). We shall start with the standard calorie model (as constructed in Machay, 2012) in the form of

$$
c_{S}=\frac{A(t) a_{T}}{L(t) c_{N}}
$$

where $c_{s}$ is the calories consumption surplus under the assumption of their equal distribution across the global population; $A(t)$ is a technological level at a given time $t ; a_{T}$ is a natural amount of calories arising on all arable land on the planet without any human intervention (briefly total calorie product of Earth); $L(t)$ is the total global population at the given time $t$; and $c_{N}$ is the minimal amount of calories biologically needed to sustain one average person over the given time period.

\section{Land degradation}

Land degradation, in general, causes decreasing yields per unit of the land or it decreases available amount of arable land. These two processes will, no matter which one outweighs the other, affect the calorie model in the same way through the $a_{T}$ variable. Both effects will decrease its value.

Assumption 1: Let us suppose that the land degrades at the constant rate $d$.

Since $d$ is a negative number affecting the total calorie product of Earth we can discount it to the "beginning" of time in a standard way

$a_{T}=a_{0} e^{-d t}$

where $a_{0}$ is the total amount of calories available before any negative effect of human activity manifested in the creative powers of nature on the total available arable land on the planet.

Applying this discounting to (1), treating the growth rates $g$ and $n$ as constants, and normalizing initial human influence in the form of $A(0)$ and $L(0)$ to 1 will lead to

$c_{S}=\frac{A(0) a_{0} e^{g t} e^{-d t}}{L(0) e^{n t} c_{N}}=\frac{a_{0}}{c_{N}} e^{(g-d-n) t}$.

The calories consumption surplus is changing in time, naturally, and is dependent on rates changing the population, technological level and availability of land.

The stationary state is given by a situation when the product of earth is just enough to sustain the existing population. Hence, the natural limit is imposed on further growth of population. In the calorie model the stationary state is easily expressed as $c_{s}=1$. Substituting one into (3) we can easily express the time to the stationary state as

$$
\begin{aligned}
& \frac{c_{N}}{a_{0}}=e^{(g-d-n) t} \\
& \log c_{N}-\log a_{0}=(g-d-n) t \\
& t_{p}=\frac{\log c_{N}-\log a_{0}}{g-d-n}
\end{aligned}
$$


where $t_{p}$ represents time to the stationary state. Since the expression $\log c_{N}-\log a_{0}$ is a negative number for the stationary state to come must be true that

$g-d-n<0$.

Hence, the first theorem can be drawn.

Theorem 1: For the stationary state to come the combined rates of population growth and land degradation must be greater than the rate of growth of technological level.

The theorem 1 is intuitive. For stationary state to come the better technological level of society must not exceed the powers moving the economy towards the stationary state. Otherwise there would not be any natural limit imposed to the growth of global population.

From reasons discussed in previous part the land degradation is a larger source of worries than the growth of population since the growth of total world population seems to decelerate. On the other hand, the externalities of human activity influencing the natural productive power of land seem to be strong. The amount of land degradation accelerated over the last few decades. Let us examine what the acceleration of land degradation will do with the stationary state from the temporal point of view. The effect of change can be expressed as

$\frac{\delta t_{p}}{\delta d}=\frac{\log c_{N}-\log a_{0}}{(d+n-g)^{2}}<0$.

An increase in the degradation rate will shorten the time to the stationary state.

Theorem 2: The increase of the land degradation rate will move the stationary state closer to the present day.

For examination of changes in the pace of the stationary state we will use the second partial derivative. Hence

$\frac{\delta^{2} t_{p}}{\delta d^{2}}=-\frac{2\left(\log c_{N}-\log a_{0}\right)}{(d+n-g)^{3}}>0$.

Since (5) must be true for the stationary state to come the expression in (7) is a positive real number. Another theorem can be drawn from the analysis.

Theorem 3: The more the land degradation rate will increase the more accelerated the coming of the stationary state will be.

The next logical step is to explore the degree of responsiveness of the stationary state to the change in the land degradation rate. Let's call the responsiveness the land degradation elasticity of the stationary state $\epsilon_{d}$. Such as it can easily be expressed as

$\epsilon_{d}=\frac{d}{t_{p}} \cdot \frac{\delta t_{p}}{\delta d}=\frac{d}{t_{p}} \cdot \frac{\log c_{N}-\log a_{0}}{(d+n-g)^{2}}=$

$$
\begin{aligned}
& =\frac{d\left(\log c_{N}-\log a_{0}\right)}{\frac{\left(\log c_{N}-\log a_{0}\right)(d+n-g)^{2}}{(g-d-n)}}=\frac{d(g-d-n)}{(d+n-g)^{2}}= \\
& \epsilon_{d}=-\frac{d}{(d+n-g)} .
\end{aligned}
$$

Since (5) must be true the land degradation elasticity of the stationary state is negative. The negative relation holds for $(4,6$, and 8$)$.

\section{The dynamics of the stationary state}

However, the elasticity coefficient is dependent not only on $d$ but on other two rates and their proportion as well. Hence,

$$
\begin{gathered}
-1<\in_{d}<0 \quad\left\{\begin{array}{c}
d<d+n-g \\
g<n
\end{array}\right. \\
\in_{d}<-1 \quad\left\{\begin{array}{c}
d>d+n-g \\
g>n
\end{array} .\right.
\end{gathered}
$$

Notice that the degree of responsiveness is inelastic in the case when the rate of technological growth is unable to compensate for the growth of population.

Theorem 4: When growth of population overtakes the growth of the technological level the change in the land degradation rate will affect the stationary state in a lower proportion.

In times the population growth creates larger stress in the society the relative importance of change in productive power of land or its decreasing quantity will play a less acute role in the society when discussing the stationary state.

Theorem 5: When growth of population will be sufficiently compensated by the growth of the technological level the change in the land degradation rate will affect the stationary state in larger proportion.

In times the technological growth will sufficiently compensate the population growth the change in the land degradation will affect the stationary state with larger proportion. In this situation the movement of the stationary state is more sensitive to changes in the land degradation rate.

The $\epsilon_{\mathrm{d}}$ shows the interconnectedness of the rates and their changes in relation to the dynamics of the stationary state. It is useful to express other degrees of responsiveness. The population growth elasticity of the stationary state can be expressed and derived in a similar way as the land degradation elasticity as

$\epsilon_{n}=-\frac{n}{(d+n-g)}$.

The technological growth elasticity will be derived properly due to its opposite sign as 


$$
\begin{aligned}
& \in_{g}=\frac{g}{t_{p}} \cdot \frac{\delta t_{p}}{\delta g}=\frac{g}{t_{p}} \cdot \frac{-\left(\log c_{N}-\log a_{0}\right)}{(g-n-d)^{2}}= \\
& =-\frac{g(g-d-n)\left(\log c_{N}-\log a_{0}\right)}{\left(\log c_{N}-\log a_{0}\right)(g-d-n)^{2}}=-\frac{g}{(g-d-n)}= \\
& \in_{g}=\frac{g}{d+n-g} .
\end{aligned}
$$

The simultaneous changes can be expressed via the sum of all elasticities as

$$
\sum \in_{i}=-\frac{d}{(d+n-g)}-\frac{n}{(d+n-g)}+\frac{g}{(d+n-g)}=-1 .
$$

The dynamic form of the stationary state with all rates treated as variables is homogeneous of degree -1 .

Proof: Let us use the Euler's theorem.

$$
\frac{\delta t_{p}}{\delta d} \cdot d+\frac{\delta t_{p}}{\delta g} \cdot g+\frac{\delta t_{p}}{\delta n} \cdot n=k t_{p}
$$

where $k$ represents degree of homogeneity.

$$
\begin{aligned}
& \frac{\log c_{N}-\log a_{0}}{(d+n-g)^{2}} \cdot d-\frac{\log c_{N}-\log a_{0}}{(d+n-g)^{2}} \cdot g+\frac{\log c_{N}-\log a_{0}}{(d+n-g)^{2}} \cdot n=k \frac{\log c_{N}-\log a_{0}}{g-d-n} \\
& \frac{\left(\log c_{N}-\log a_{0}\right)(d-g+n)}{(d+n-g)^{2}}=k \frac{\log c_{N}-\log a_{0}}{g-d-n}
\end{aligned}
$$

$-1=k$
If all rates were to double the time to the stationary state would change by the $2^{-1}$ factor. Basically the stationary state would take place twice sooner than before the change.

Theorem 6: If all rates were to increase by the same factor $k$ the stationary state would take place $k$ times sooner.

After exploring the land degradation dynamics and simultaneous rates change dynamics there is only one aspect worthy of exploration - the interconnectedness dynamics.

For exploring the interaction between the variables of interest further assumption must be made.

Assumption 2: Let us suppose that the change in one rate must be compensated by the changes in other rates in a way it does not affect the coming of the stationary state.

Change in one rate must be perfectly balanced by changes in other rates in order to have no effect on the stationary state. Assumption 2 can be easily rewritten in a form as

$$
\begin{aligned}
& \sum \epsilon_{i}=0 \\
& \text { which will lead to }
\end{aligned}
$$

$g=d+n$.

The change in the population growth for example must be compensated in the same absolute order by the technological growth. The same can be said about land degradation.

Theorem 7: The rates inter-compensate each other in a linear fashion.

\section{CONCLUSIONS}

This paper explored implications of additional variable in the Malthusian framework. While including the land degradation rate is relatively easy in the mathematical way it is much more complicated to do the same in the abstract and deductive environment of the eight- and nineteenth century.

This paper, thus, explains why the land degradation was beyond the Malthus' reach even though he was, without any doubt, aware of the factor. The dynamics is simply too complicated and too conditional. Further addition of this paper is the explanation of the interconnectedness of variables while examining the stationary state. Since we live in times of high technological growth and falling fertility rates in the developed world the land degradation is a major factor explaining the dynamics of the stationary state as proven in the paper. It is more sensitive to the land degradation rate than to the population growth.

The next logical step in the area of the stationary state research within the Malthusian framework is, for example, to estimate the expanded model on the real data. Not only using our contemporary data which are available but the estimated data from the Malthusian days. This hypothetical estimate of nineteenth century stationary state might prove Malthus right in the context of his time. Further possible way of theoretical research is to make the growth rates endogenous - time and state dependent.

\section{REFERENCES}

BABE, R. E. 2006. Culture of Ecology: Reconciling Economics and Environment. Toronto: University of Toronto Press. BERGER, S. and FORSTATER, M. 2007. Toward a Political Institutionalist Economics: Kapp's Social Costs, Lowe's Instrumental Analysis, and the European Institutionalist Approach to Environmental Policy. Journal of Economic Issues, 41(2): 539-546. 
BOWERS, S., RYAN, C. and JONES, X. H. 2017. Understanding agricultural drivers of deforestation through remote sensing: Opportunities and limitations in sub-Saharan Africa. London: International Institute for Environment and Development.

CAMERON, T. A. 1997. Environmental Economics and Ecological Economics. Science, 277(5324): 300-301.

CARLSSON, F. and JOHANSSON-STENMAN, O. 2012. Behavioral Economics and Environmental Policy. Annual Review of Resource Economics, 4: 75-99.

CASTLE, E. N. 1999. Natural Resources and Environmental Economics: A Retrospective View. Review of Agricultural Economics, 21(2): 288-304.

DIETZ, F. J. and VAN DER STRAATEN, J. 1992. Rethinking Environmental Economics: Missing Links between Economic Theory and Environmental Policy. Journal of Economic Issues, 26(1): 27-51.

GONZALEZ-JARAMILLO, V., FRIES, A., ROLLENBECK, R., PALADINES, J., ONATE-VALDIVIESO, F. and BENDIX, J. 2016. Assessment of Deforestation during the last decades in Ecuador Using NOAA-AVHRR Satellite Data. Erdkunde, 70(3): 217-235.

GOWDY, J. M. 2004. The Revolution in Welfare Economics and Its Implications for Environmental Valuation and Policy. Land Economics, 80(2): 239-257.

KLING, C. L., SEGERSON, K. and SHOGREN, J. F. 2010. Environmental Economics: How Agricultural Economists Helped Advance the Field. American Journal of Agricultural Economics, 92(2): 487-505.

MACHAY, M. 2012. The Principle of Population for the $21^{\text {st }}$ Century: The Never Coming Stationary State. Review of Economic Perspectives - Národohospodárský obzor, 12(3): 168-184.

MACHAY, M. 2016. Death Rates in the Calorie Model. Acta Universitatis Agriculturae et Silviculturae Mendelianae Brunensis, 64(6): 2053-2058.

MAYHEW, R. 2014. Malthus and the Making of Environmental Economics. In: Malthus. Cambridge, MA: Harvard University Press, pp. 103-127.

NADEAU, R. L. 2006. The Environmental Endgame: Mainstream Economics, Econological Disaster, and Human Survival. New Brunswick, NJ: Rutgers University Press.

OATES, W. E. 1990. Economics, Economists, and Environmental Policy. Eastern Economic Journal, 16(4): $289-296$. ROSA, I. M. D., SOUZA JR., C. and EWERS, R. M. 2012. Changes in Size of Deforested Patches in the Brazilian Amazon. Conservation Biology, 26(5): 932-934.

SODERBAUM, P. 1990. Neoclassical and Institutional Approaches to environmental Economics. Journal of Economic Issues, 24(2): 481-492.

TIMMINS, C. and SCHLENKER, W. 2009. Reduced-Form Versus Structural Modeling in Environmental and Resource Economics. Annual Review of Resource Economics, 1: 351-380. 